\title{
CLONAGEM DE CANISTEL POR ESTAQUIA ${ }^{1}$
}

\author{
FERNANDO MARCELO CHIAMOLERA ${ }^{2}$, ADRIANA DE CASTRO CORREIA DA SILVA ${ }^{3}$, \\ RAFAEL ROVERI SABIÃO ${ }^{4}$, TATIANA PAGAN LOEIRO DA CUNHA ${ }^{5}$, \\ ANTONIO BALDO GERALDO MARTINS ${ }^{6}$
}

RESUMO - O canistel é nativo do sul do México e América Central e seus frutos apresentam elevado teor de carotenoides e vitamina A. Sua propagação é feita via sementes, resultando em considerável variabilidade genética entre os indivíduos, sendo a propagação vegetativa preferível, a fim de fixar características desejáveis. Assim, o objetivo deste trabalho foi avaliar a propagação vegetativa por estaquia de ramos semi-herbáceos de canistel, em função de quatro genótipos e quatro concentrações de AIB. Foram utilizadas estacas semiherbáceas apicais, mantidas com um par de folhas, sob nebulização intermitente, por 120 dias. O delineamento experimental foi o inteiramente casualizado, em esquema fatorial $4 \times 4$ (genótipos de canistel $\times$ concentrações de AIB), com quatro repetições e dez estacas por parcela. Foram avaliados a porcentagem de sobrevivência, a retenção foliar, o enraizamento, o calejamento, o número e o comprimento médio de raízes por estaca. $\mathrm{O}$ genótipo PC-1 foi superior aos demais, em todas as variáveis avaliadas, com destaque para o enraizamento das estacas, superior a 60\%. As concentrações de AIB $\left(0 ; 1.000 ; 3.000\right.$ e $\left.5.000 \mathrm{mg} \mathrm{L}^{-1}\right)$ não influenciaram na sobrevivência, retenção foliar e enraizamento das estacas, mas aumentaram o número e o comprimento de raízes em relação ao tratamento-controle (sem AIB). Há diferença na capacidade de enraizamento das estacas entre os genótipos de canistel, sendo a melhor resposta obtida com PC-1. A concentração de $3.000 \mathrm{mg} \mathrm{L}^{-1} \mathrm{de}^{-}$ AIB resulta em maior número e comprimento de raízes nas estacas de canistel.

Termos para indexação: Pouteria campechiana, AIB, enraizamento, produção de mudas.

\section{CLONING OF YELLOW SAPOTE BY CUTTING}

\begin{abstract}
The yellow sapote is native to southern Mexico and Central America, and its fruits have high content of carotenoids and vitamin A. Its propagation is done through seed, resulting in considerable genetic variability among individuals, being preferable vegetative propagation, in order to fix desirable characteristics. Thus, the aim of this study was to evaluate the vegetative propagation by cuttings of semiherbaceous branches of yellow sapote, according to four genotypes and four concentrations of IBA. Cuttings were semi-herbaceous apical, maintained with a pair of leaves, under intermittent mist for 120 days. A completely randomized experimental design was use, in a $4 \times 4$ factorial (yellow sapote genotypes $\times$ IBA concentrations) with four replicates and ten cuttings per plot. It was evaluate the percentage of survival, leaf retention, rooting, callus, average number and length of roots per cutting. The PC-1 genotype was superior to others in all variables, with emphasis on the rooting of cuttings exceeding $60 \%$. The IBA concentrations $\left(0 ; 1,000 ; 3,000\right.$ and $\left.5,000 \mathrm{mg} \mathrm{L}^{-1}\right)$ did not influence survival, leaf retention and rooting but increased the number and length of roots compared to control treatment (without IBA). There were differences in rooting capacity to among genotypes of yellow sapote, being the best response obtained with PC-1. The IBA concentration 3,000 $\mathrm{mg} \mathrm{L}^{-1}$ results in greater number and length of roots in the yellow sapote cuttings. Index terms: Pouteria campechiana, IBA, rooting, seedling production.
\end{abstract}

${ }^{1}$ (Trabalho 312-13). Recebido em: 26-08-2013. Aceito para publicação em: 08-07-2014.

${ }^{2}$ Eng. Agr., Doutorando em Agronomia (Produção Vegetal), Universidade Estadual Paulista, Faculdade de Ciências Agrárias e Veterinárias, Via de Acesso Prof. Paulo Donato Castellane, s/n, 14884-900, Jaboticabal, São Paulo, Brasil. E-mail: chiamolera@hotmail.com ${ }^{3}$ Eng. Agr., Doutora em Agronomia (Produção Vegetal), Agência de Desenvolvimento Agrário e Extensão Rural de Mato Grosso do Sul, Centro de Pesquisa e Capacitação da Agraer - CEPAER, Rodovia BR-080, km 10, 79114-005, Campo Grande, Mato Grosso do Sul, Brasil. E-mail: adrianaccsilva@yahoo.com.br

${ }^{4}$ Eng. Agr., Doutorando em Agronomia (Produção Vegetal), Universidade Estadual Paulista, Faculdade de Ciências Agrárias e Veterinárias, Via de Acesso Prof. Paulo Donato Castellane, s/n, 14884-900, Jaboticabal, São Paulo, Brasil. E-mail: rrsabiao@yahoo.com.br ${ }^{5}$ Eng. Agr., Doutoranda em Agronomia (Produção Vegetal), Universidade Estadual Paulista, Faculdade de Ciências Agrárias e Veterinárias, Via de Acesso Prof. Paulo Donato Castellane, s/n, 14884-900, Jaboticabal, São Paulo, Brasil. E-mail: tatiana.pagan@hotmail.com ${ }^{6}$ Eng. Agr., Professor Assistente Doutor, Departamento de Produção Vegetal, Universidade Estadual Paulista, Faculdade de Ciências Agrárias e Veterinárias, Via de Acesso Prof. Paulo Donato Castellane, s/n, 14884-900, Jaboticabal, São Paulo, Brasil. E-mail: baldo@ fcav.unesp.br 


\section{INTRODUÇÃO}

O canistel [Pouteria campechiana (Kunth) Baehni; Sapotaceae] é uma frutífera originária do sul do México e América Central. Além dessas regiões, é cultivado nos Estados Unidos da América (sul da Flórida) e em alguns países da América do Sul e Ásia (KONG et al., 2013). É uma espécie alógama com flores hermafroditas localizadas nas axilas das folhas ou em nós sem folhas e as plantas, em média, atingem $8 \mathrm{~m}$ de altura. Em função da fecundação cruzada, os frutos são variáveis entre os genótipos quanto à forma e tamanho, sendo redondos, ovais ou ovoides, com ou sem ápice pontiagudo e à medida que amadurecem, a casca torna-se amarela e lisa.

A polpa do canistel possui baixa umidade, e a quantidade de carotenoides, reconhecidos pela atividade antioxidante, é elevada, com destaque para neoxantina e violaxantina que apresentam teores comparáveis aos encontrados em frutos de mamey (TORRES-RODRÍGUEZ et al., 2011) e em alimentos com amplo consumo mundial, como citrus (CARMONA et al., 2012) e batata (FERNANDEZOROZCO et al., 2013). Sob o ponto de vista nutricional, o teor de vitamina A é elevado, e um copo de suco contendo $100 \mathrm{~g}$ de polpa de cansitel pode suprir aproximadamente $15 \%$ das necessidades diárias de vitamina A para crianças (AGOSTINICOSTA et al., 2010).

Dado o grande potencial de cultivo de frutíferas exóticas e a crescente demanda do mercado consumidor por produtos diferenciados, sendo aroma, sabor e valor nutricional valorizados, colocam o canistel em destaque. Porém, a propagação desta espécie é via sementes, resultando em grande variabilidade genética entre os genótipos, iniciando a produção com aproximadamente 6 anos, com considerável variação nas características físicas, químicas e na produtividade entre os indivíduos.

Assim, a propagação vegetativa é preferível a fim de fixar características desejáveis, reproduzir os melhores genótipos e reduzir o período de juvenilidade, sendo a clonagem por ramos apicais uma das técnicas mais utilizadas. A presença de folhas garante a sobrevivência das estacas, pois os carboidratos sintetizados pela fotossíntese, o fornecimento de auxinas e outras substâncias são fundamentais para o desenvolvimento e o crescimento das raízes, estimulando a divisão, o alongamento e a diferenciação celular (AHKAMI et al., 2013).

$\mathrm{Na}$ propagação vegetativa por estaquia, o uso de reguladores de crescimento, como o ácido indolbutírico (AIB), pode ser fundamental para a formação e a porcentagem de estacas enraizadas. Trabalhos com diversas espécies vegetais e concentrações de AIB, geralmente entre 0 (zero) e $5.000 \mathrm{mg} \mathrm{L}^{-1}$, demonstram grandes variações quanto ao enraizamento das estacas (BALESTRI et al., 2012; CARTABIANO; LUBELL, 2013; LING et al., 2013; SARROPOULOU et al., 2013a; SEVIK; GUNEY, 2013). Em função da escassez de informações sobre a clonagem de canistel, o objetivo deste trabalho foi avaliar a propagação vegetativa por estaquia de ramos semi-herbáceos de canistel, em função de quatro genótipos e quatro concentrações de AIB.

\section{MATERIAL E MÉTODOS}

O experimento foi realizado no Ripado de Fruticultura $\left(21^{\circ} 14^{\prime} 33^{\prime \prime} \mathrm{S}, 48^{\circ} 17^{\prime} 02^{\prime \prime} \mathrm{W} ; 563\right.$ $\mathrm{m}$ de altitude) da Faculdade de Ciências Agrárias e Veterinárias, Universidade Estadual Paulista, Câmpus de Jaboticabal. O clima da região é subtropical, do tipo Aw (classificação climática de Köppen), relativamente seco no inverno, com chuvas no verão, temperatura e precipitação média anual de $22,5^{\circ} \mathrm{C}$ e $1.425 \mathrm{~mm}$, respectivamente.

O experimento foi conduzido de 23 de janeiro a 23 de maio de 2013, em câmara de nebulização intermitente, sob telado com 50\% de luminosidade. $\mathrm{O}$ delineamento experimental foi inteiramente casualizado, em esquema fatorial $4 \times 4$ (genótipos de canistel $\times$ concentrações de AIB), com quatro repetições e dez estacas por parcela, totalizando 640 estacas. As matrizes de canistel que forneceram o material vegetativo para propagação, pertencem ao Banco Ativo de Germoplasma do Departamento de Produção Vegetal, e foram selecionadas de quatro genótipos com aproximadamente 28 anos, denominados PC-1, PC-2, PC-3 e PC-4, em função do tamanho dos frutos e da produtividade.

Estacas semi-herbáceas foram retiradas da região apical de ramos em crescimento vegetativo, em média com $20 \mathrm{~cm}$ de comprimento, foram mantidas com um par de folhas inteiras. $\mathrm{Na}$ base de cada estaca, foi efetuado um corte em bisel e um corte perpendicular no ápice; em seguida, tratadas com AIB, nas concentrações 0 (zero; tratamentocontrole); $1.000 ; 3.000$ e 5.000 mg.L ${ }^{-1}$, por imersão da extremidade basal, por 5 segundos.

As estacas foram dispostas em bandejas de polietileno perfuradas $(36 \times 26 \times 7 \mathrm{~cm})$, contendo vermiculita expandida, textura média, mantidas sob nebulização intermitente ( 5 segundos de molhamento e 45 segundos de intervalo) por 120 dias. As avaliações foram quanto à porcentagem de sobrevivência (estacas que permaneceram verdes), 
retenção foliar (estacas que mantiveram, no mínimo, uma folha), enraizamento (estacas que emitiram, pelo menos,uma raiz), calejamento, número e comprimento médio de raízes por estaca.

Para análise, os valores das variáveis; porcentagem de sobrevivência, retenção foliar, enraizamento e calejamento das estacas foram transformados em arco-seno $\sqrt{\frac{x}{100}}$ e, número e comprimento médio de raízes em $\sqrt{x+0,5}$. Os dados referentes aos genótipos foram submetidos à análise de variância, pelo teste $\mathrm{F}$; e as médias dos tratamentos, comparadas pelo teste de Tukey, a 1\%. Os dados quantitativos (concentração de AIB) foram analisados por meio de regressão polinomial. Estimaram-se os coeficientes de correlação entre as variáveis ,pelo método de Pearson.

\section{RESULTADOS E DISCUSSÃO}

Houve diferença entre os genótipos de canistel para todas as variáveis analisadas, com destaque para o genótipo PC-1 (Tabela 1). A análise de correlação mostrou efeito positivo entre sobrevivência, retenção foliar, enraizamento, número e comprimento de raízes das estacas (Tabela 2). Isto pode ser explicado por a manutenção foliar fornecer carboidratos aos primórdios radiculares, e as raízes adventícias formadas absorvem água do substrato, contribuindo para a sobrevivência das estacas. Estas afirmações são suportadas em função de existirem relações positivas entre fotossíntese, acúmulo de carboidratos e número de raízes formadas (SARROPOULOU et al., 2013b).

$\mathrm{O}$ enraizamento das estacas de canistel tem correlação positiva com retenção foliar, número e comprimento de raiz e sobrevivência (Tabela 2). A retenção foliar é fundamental para o enraizamento, em função do fornecimento de auxinas sintetizadas durante a fotossíntese e translocadas para a base da estaca em resposta à excisão da planta-matriz, contribuindo para a indução e a iniciação do desenvolvimento de raízes adventícias. O sucesso da indução do enraizamento também é resultado da interação entre diversos fatores, como níveis hormonais endógenos, condições climáticas, nutrição das plantas-matrizes, entre outros, como o potencial genético, que pode explicar o maior enraizamento das estacas do genótipo PC-1 (AHKAMI et al., 2013).

Conforme a porcentagem de enraizamento das estacas dos genótipos de canistel aumentou, maiores foram o número e o comprimento de raízes (Tabela 1), fato confirmado por meio da correlação positiva entre as três variáveis (Tabela 2). Após desencadear o processo de indução do desenvolvimento dos primórdios radiculares, este evento é cessado em detrimento do crescimento/ alongamento radicular. Evidências apontam que este processo é regulado por estrigolactonas, que podem reduzir a atividade cambial necessária para a indução do desenvolvimento de raízes adventícias, mas, em contrapartida, estimulam o crescimento secundário das raízes (AGUSTI et al., 2011).

Por outro lado, com o aumento da formação de calos, na base das estacas, houve menor enraizamento das estacas, mostrando que estes processos são antagônicos, por competirem por energia, e em estacas com calo muito pronunciado, frequentemente não há emissão de raízes (Tabelas 1 e 2). A formação de calo na base da estaca ocorre quando o floema e o xilema são lesionados, desenvolvendo uma massa irregular de células parenquimatosas em vários estádios de lignificação. Porém, a produção de calos pode ser benéfica para espécies que enraízam lentamente, como o canistel, pois retardam o aparecimento de podridões, embora o crescimento de calos, às vezes, possa interferir na absorção de água pela estaca (OLIVEIRA; RIBEIRO, 2013).

Em ralação ao uso de AIB, as concentrações avaliadas não influenciaram na sobrevivência (>87\%), retenção foliar $(>87 \%)$ e enraizamento das estacas $(<20 \%)$ (Figura 1A). Porém, com a aplicação de AIB, há aumento nos níveis de auxina que pode retardar o início da abscisão foliar e elevar a concentração de clorofila nas folhas, como observado com o porta-enxerto de cerejeira ' $\mathrm{M} \times \mathrm{M}$ 14', contribuindo para a sobrevivência das estacas (SORROPOULOU et al., 2013b).

Com a aplicação de $3.000 \mathrm{mg} \mathrm{L}^{-1}$ de AIB, o número de raízes dobrou em relação ao tratamentocontrole (sem AIB). Entre as concentrações de 3.000 e $5.000 \mathrm{mg} \mathrm{L}^{-1}$ de AIB, o número de raízes ficou praticamente estabilizado (Figura 1B). O comprimento de raiz teve comportamento semelhante ao do número de raízes, com incremento de aproximadamente $65 \%$ na extensão das raízes, quando utilizados $3.000 \mathrm{mg}$ $\mathrm{L}^{-1}$ de AIB em comparação ao controle; apesar de, após esta concentração, ter ocorrido um declínio de cerca de 50\% no comprimento das raízes (Figura 1C).

A rizogênese é estimulada por níveis de auxina (variável entre espécies e genótipos) que promove a divisão celular e mantém a viabilidade das células durante o desenvolvimento das raízes adventícias. Com a aplicação de elevadas concentrações de AIB (>3.000 $\mathrm{mg} \mathrm{L}^{-1}$ para estacas de canistel), o conteúdo intracelular de auxina aumentou e pode ter atingido nível tóxico, reduzindo a divisão celular e o número de raízes (LING et al., 2013; SARROPOULOU et al., 2013a). 
O alongamento radicular é inibido por concentrações elevadas de auxina, ajudando a explicar a redução no comprimento das raízes a partir de $3.000 \mathrm{mg} \mathrm{L}^{-1}$ de AIB (SCHEITZ et al., 2013). Outro fator que pode ter contribuído para a redução no alongamento das raízes, é a competição por carboidratos, já que a vermiculita, apesar de suas excelentes propriedades físicas (elevada capacidade adsorção de água e aeração), é um substrato de baixa fertilidade.

TABELA 1 - Sobrevivência (SB), retenção foliar (RF), enraizamento (ER), calejamento (CL), número de raiz (NR) e comprimento de raiz (CR) de estacas de canistel, em função dos genótipos.

\begin{tabular}{lcccccc}
\hline Genótipos & $\mathbf{S B}^{\mathbf{z}}$ & $\mathbf{R F}^{\mathbf{z}}$ & $\mathbf{E R}^{\mathbf{z}}$ & $\mathbf{C L}^{\mathbf{z}}$ & $\mathbf{N R}^{\mathbf{z}}$ & $\mathbf{C R}^{\mathbf{z}}$ \\
\hline PC-1 & $96,88 \mathrm{a}$ & $96,88 \mathrm{a}$ & $61,88 \mathrm{a}$ & $32,50 \mathrm{c}$ & $3,01 \mathrm{a}$ & $4,69 \mathrm{a}$ \\
PC-2 & $85,00 \mathrm{~b}$ & $85,63 \mathrm{~b}$ & $0,00 \mathrm{c}$ & $75,63 \mathrm{a}$ & $0,00 \mathrm{c}$ & $0,00 \mathrm{~b}$ \\
PC-3 & $85,00 \mathrm{~b}$ & $84,38 \mathrm{~b}$ & $6,88 \mathrm{~b}$ & $68,75 \mathrm{a}$ & $0,58 \mathrm{~b}$ & $0,98 \mathrm{~b}$ \\
PC-4 & $88,75 \mathrm{~b}$ & $86,88 \mathrm{~b}$ & $0,69 \mathrm{c}$ & $55,38 \mathrm{~b}$ & $0,06 \mathrm{c}$ & $0,54 \mathrm{~b}$ \\
\hline Teste F & $4,81^{* *}$ & $4,35^{* *}$ & $212,65^{* *}$ & $31,65^{* *}$ & $112,95^{* *}$ & $40,74^{* *}$ \\
CV (\%) & 6,04 & 6,51 & 29,19 & 12,85 & 18,86 & 36,22 \\
\hline
\end{tabular}

${ }^{\mathrm{z}}$ Dados originais. Para análise, os valores em porcentagem (SB, RF, ER e CL) foram transformados em arco-seno $\sqrt{\frac{x}{100}}$.
NR e CR foram transformados em $\sqrt{x+0,5}$.

Médias seguidas por letra diferente, na coluna, diferem pelo teste de Tukey $(\mathrm{p}<0,01) ;{ }^{* *}=$ significativo a $1 \%$; ns $=$ não significativo a $5 \% ; \mathrm{CV}=$ coeficiente de variação.

TABELA 2 - Matriz de correlação de Pearson entre as variáveis sobrevivência (SB), retenção foliar (RF), enraizamento (ER), calejamento (CL), número de raiz (NR) e comprimento de raiz (CR) de estacas de canistel.

\begin{tabular}{|c|c|c|c|c|c|c|}
\hline Variável & SB & RF & ER & CL & NR & CR \\
\hline SB & 1,000 & $\begin{array}{l}0,955^{* *} \\
0,000\end{array}$ & $\begin{array}{l}0,685^{* *} \\
0,003\end{array}$ & $\begin{array}{c}-0,492^{\text {ns }} \\
0,053\end{array}$ & $\begin{array}{l}0,653^{* *} \\
0,006\end{array}$ & $\begin{array}{l}0,554^{* *} \\
0,026\end{array}$ \\
\hline RF & & 1,000 & $\begin{array}{l}0,780^{* *} \\
0,000\end{array}$ & $\begin{array}{c}-0,561^{*} \\
0,024\end{array}$ & $\begin{array}{l}0,744^{* *} \\
0,001\end{array}$ & $\begin{array}{l}0,653^{* *} \\
0,006\end{array}$ \\
\hline ER & & & 1,000 & $\begin{array}{c}-0,808^{* *} \\
0,000\end{array}$ & $\begin{array}{l}0,949^{* *} \\
0,000\end{array}$ & $\begin{array}{l}0,929^{* *} \\
0,000\end{array}$ \\
\hline CL & & & & 1,000 & $\begin{array}{c}-0,764^{* *} \\
0,001\end{array}$ & $\begin{array}{c}-0,806^{* *} \\
0,000\end{array}$ \\
\hline NR & & & & & 1,000 & $\begin{array}{l}0,873^{*} \\
0,000\end{array}$ \\
\hline CR & & & & & & 1,000 \\
\hline
\end{tabular}

${ }^{* *}=$ Significativo a $1 \% ;{ }^{*}=$ Significativo a $5 \%$; ns = Não significativo a $5 \%$. 

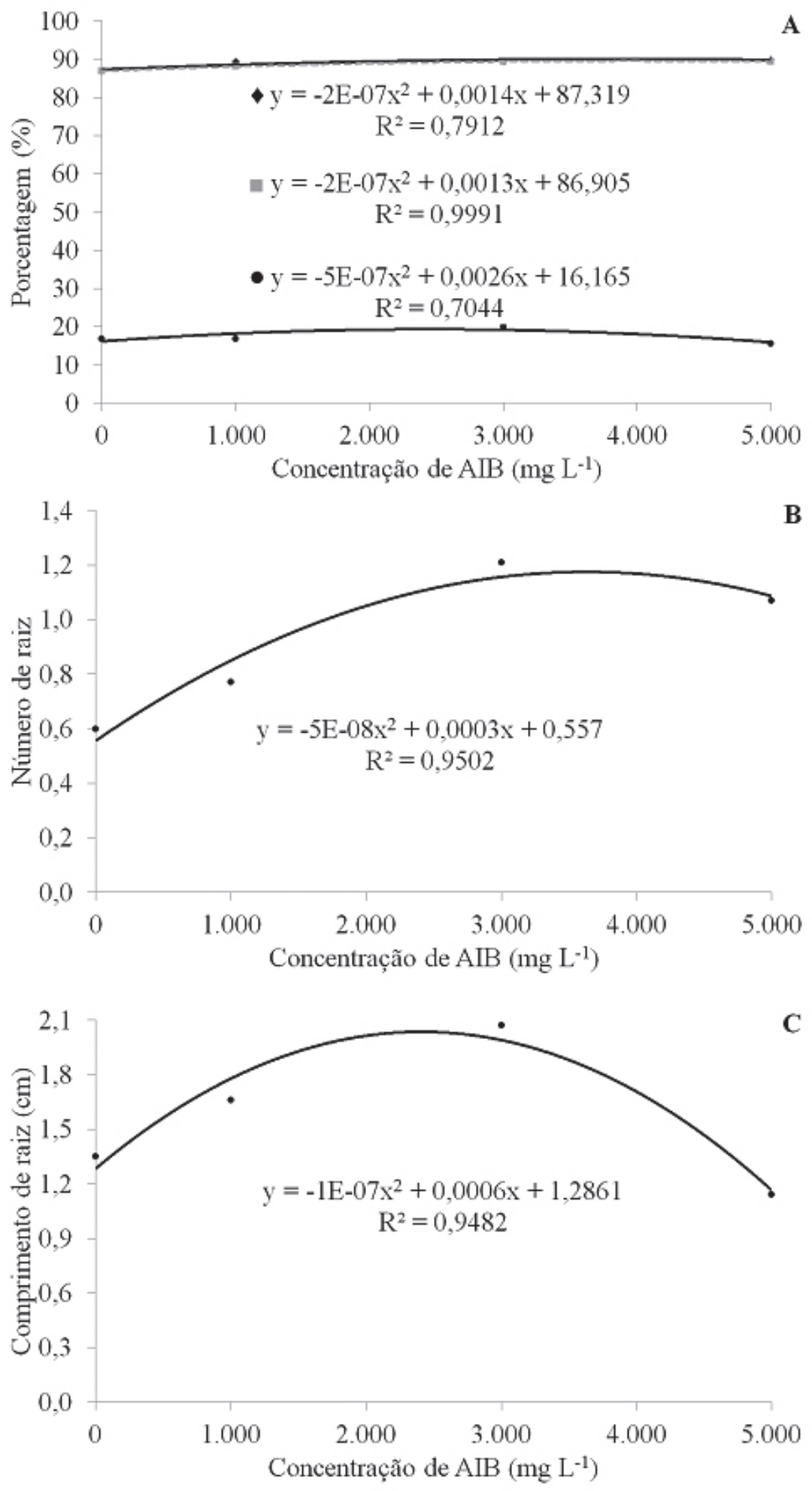

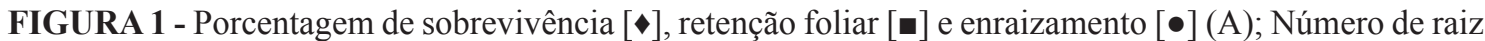
(B); Comprimento de raiz em estacas de canistel, em função da concentração de AIB (C). 


\section{CONCLUSÃO}

Há diferença na capacidade de enraizamento das estacas entre os genótipos de canistel, sendo a melhor resposta obtida com PC-1. A concentração de $3.000 \mathrm{mg} \mathrm{L}^{-1}$ de AIB resulta em maior número e comprimento de raízes nas estacas de canistel.

\section{REFERÊNCIAS}

AGOSTINI-COSTA, T. S.; WONDRACEK, D. C.; LOPES, R. M.; VIEIRA, R. F. FERREIRA, F. R. Composição de carotenoides em canistel [Pouteria campechiana (Kunth) Baehni]. Revista Brasileira de Fruticultura, Jaboticabal, v. 32, n. 3, p. 903-906, 2010 .

AGUSTI, J.; HEROLD, S.; SCHWARZ, M.; SANCHEZ, P.; LJUNG, K.; DUN, E. A.; BREWER, P. B.; BEVERIDGE, C. A.; SIEBERER, T.; SEHR, E. M.; GREB, T. Strigolactone signaling is required for auxin-dependent stimulation of secondary growth in plants. Proceedings of the National Academy of Sciences of the United States of America, Washington, v. 108, n. 50, p. 20.242-20.247, 2011.

AHKAMI, A. H.; MELZER, M.; GHAFFARI, M. R.; POLLMANN, S.; JAVID, M. G.; SHAHINNIA, F.; HAJIREZAEI, M. R.; DRUEGE, U. Distribution of indole-3-acetic acid in Petunia hybrida shoot tip cuttings and relationship between auxin transport, carbohydrate metabolism and adventitious root formation. Planta, Heidelberg, v. 238, n. 3, p. 499517, 2013.

BALESTRI, E.; VALLERINI, F.; CASTELLI, A.; LARDICCI, C. Application of plant growth regulators, a simple technique for improving the establishment success of plant cuttings in coastal dune restoration. Estuarine, Coastal and Shelf Science, London, v. 99, p. 74-84, 2012.

CARMONA, L.; ZACARÍAS, L.; RODRIGO, M. J. Stimulation of coloration and carotenoid biosynthesis during postharvest storage of 'Navelina' orange fruit at $12{ }^{\circ} \mathrm{C}$. Postharvest Biology and Technology, Amsterdam, v. 74, p. 108-117, 2012.

CARTABIANO, J. A.; LUBELL, J. D. Propagation of four underused native species from softwood cuttings. HortScience, Alexandria, v. 48, n. 8, p. 1018-1020, 2013.
FERNANDEZ-OROZCO, R.; GALLARDOGUERRERO, L.; HORNERO-MÉNDEZ, D. Carotenoid profiling in tubers of different potato (Solanum sp) cultivars: Accumulation of carotenoids mediated by xanthophyll esterification. Food Chemistry, Amsterdam, v. 141, n. 3, p. 2864-2872, 2013.

KONG, K. W.; KHOO, H. E.; PRASAD, N. K.; CHEW, L. Y.; AMIN, I. Total phenolics and antioxidant activities of Pouteria campechiana fruit parts. Sains Malaysiana, Bangi, v. 42, n. 2, p. 123-127, 2013.

LING, W. X.; ZHU, G.; ZHONG, Z. Effect of IBA on rooting from softwood cuttings of 'tetraploid locust' and associated biochemical changes. Pakistan Journal of Botany, Karachi, v. 45, n. 5, p. 1801 1806, 2013.

OLIVEIRA, M. C.; RIBEIRO, J. F. Enraizamento de estacas de Euplassa inaequalis (Pohl) Engl. de mata de galeria em diferentes estações do ano. Bioscience Journal, Uberlândia, v. 29, n. 4, p. 991-999, 2013.

SARROPOULOU, V.; DIMASSI-THERIOU, K.; THERIOS, I. Effects of exogenous L-arginine on in vitro rooting, chlorophyll, carbohydrate, and proline concentrations in the sweet cherry rootstock $\mathrm{M} \times \mathrm{M}$ 14 (Prunus avium L. $\times$ Prunus mahaleb L.). Plant Biotechnology Reports, Tokyo, v. 7, n. 4, p. 457$465,2013 b$

SARROPOULOU, V.; DIMASSI-THERIOU, K.; THERIOS, I. Indole-3-butyric acid and myo-inositol impacts on in vitro rooting of the cherry rootstocks CAB-6P and Gisela 6. Biologia Plantarum, Dordrecht, v. 57, n. 4, p. 613-619, $2013 \mathrm{a}$.

SCHEITZ, K.; LÜTHEN, H.; SCHENCK, D. Rapid auxin-induced root growth inhibition requires the TIR and AFB auxin receptors. Planta, Heidelberg, v. 238, n. 6, p. 1171-1176, 2013.

SEVIK, H.; GUNEY, K. Effects of IAA, IBA, NAA, and GA3 on rooting and morphological features of Melissa officinalis L. stem cuttings. The Scientific World Journal, New York, v. 2013, ID 909507, p. $1-5,2013$

TORRES-RODRÍGUEZ, A.; SALINAS-MORENO, Y.; VALLE-GUADARRAMA, S.; ALIA-TEJACAL, I. Soluble phenols and antioxidant activity in mamey sapote (Pouteria sapota) fruits in postharvest. Food Research International, Oxford, v. 44, n. 7, p. 1956-1961, 2011. 